\title{
Quality characteristics of cut kimchi cabbage during short-term storage depending on the packaging materials
}

\author{
Eun Ji Son ${ }^{1}$, In-Wook Hwang ${ }^{2}$, Shin-Kyo Chung ${ }^{1,2 *}$ \\ ${ }^{1}$ School of Food Science and Biotechnology, Kyungpook National University, Daegu 41566, Korea \\ ${ }^{2}$ Food and Bio-Industry Research Institute, Kyungpook National University, Daegu 41566, Korea
}

\section{절단배추의 포장재질에 따른 단기 저장 중 품질특성}

\author{
손은지 ${ }^{1} \cdot$ 황인욱 $^{2} \cdot$ 정신교 ${ }^{1,2 *}$ \\ ${ }^{1}$ 경북대학교 식품공학부, ${ }^{2}$ 경북대학교 식품생물산업연구소
}

\begin{abstract}
Fresh cut vegetables provide convenience and rapidity to consumers. However, they have a weakness with respect to their short shelf-life due to browning and quality degradation via increased respiration. To overcome this problem, the effect of packaging film on the short-term storage of cut kimchi cabbages was investigated. Polypropylene (PP), oriented polypropylene (OPP), and low-density polyethylene (LDPE) films were used as packaging film, and cut kimchi cabbages were stored in the packaging films at $5^{\circ} \mathrm{C}$ for 4 weeks. PP film packaging showed the least weight loss and soluble solids loss after 4 weeks. Titratable acidity increased during storage for all samples, however, the increase rate of titratable acidity in PP and OPP film packaging decreased, which was lower than that of LDPE film packaging. Color values decreased over time during storage. In appearance, PP film packaging was better than other films due to their high transparency. In a sensory test, there was no statistical difference among samples. Taken together, the transparent PP film packaging was more effective for short-term storage of cut kimchi cabbages. Thus, this study provides useful information for the selection of packaging materials for cut kimchi cabbage marketing.
\end{abstract}

Key words : cut kimchi cabbages, polypropylene film, short-term storage, quality

\section{서 론}

배추(Brassica rapa L. ssp. pekinensis)는 양귀비목 십자화 과의 식물로 식이섬유, 무기질 성분이 풍부해 다양한 요리 의 재료로 사용되고 있으며(1), 우리나라에서는 주로 잎사 귀를 절여서 김치의 주재료로 사용한다. 한편 최근 경제 수준의 향상과 소득의 증가에 따라 식품의 소비추세가 건강 과 편리성을 추구하게 되면서 세척, 절단, 박피 등의 과정 없이 바로 섭취하거나 조리할 수 있게 만들어 편의성과 기호성, 상품성을 증대한 신선편이 채소류의 소비가 예전

*Corresponding author. E-mail : kchung@knu.ac.kr Phone : 82-53-950-5778, Fax : 82-53-950-6772

Received 16 July 2015; Revised 18 September 2015; Accepted 21 September 2015.

Copyright (c) The Korean Society of Food Preservation. All rights reserved.
보다 증가하였다(2-4). 이러한 신선편이 채소류의 수요에 맞춰 안정된 수급의 균형을 이루기 위해 세척 방법 개선(5), 예냉(6), 데치기(7), 갈변저해제 사용(8), controlled atmosphere (CA)/modified atmosphere(MA) 저장환경(9-13), 포장 재질 선택(14-16) 등 여러 측면의 연구가 보고된 바 있다.

절단 채소는 겉절이나 공장 보급용으로 유통되어 소비자 에게 편의성과 신속성을 제공하지만, 절단에 따른 호흡율 의 증가로 인한 갈변과 품질 열화로 인해 유통기한이 짧은 것이 단점이다(1-3). 이러한 단점을 개선하기 위해 여러 포 장재를 사용하여 애호박(14), 버섯(15), 청매실(16) 등의 품 질특성에 관한 연구는 많이 이루어졌으나, 포장재에 따른 신선편이 배추의 품질변화 연구는 미비한 실정이다. Lee 등(15)의 연구에서는 polyethylene(PE) film, polyvinyl chloride(PVC) film, polypropylene(PP) film 등이 이용되었 으며, 포장재의 경우 film은 종류와 두께에 따라 산소 및 이산화탄소 투과율이 다르며 이는 과채류의 품질변화에 
중요한 영향을 준다고 알려져 있다(15).

본 연구에서는 절단 배추 저장을 위한 적절한 포장재 선택에 대한 연구를 실행하였다. 국내산 배추를 일정한 크 기로 절단하여 polypropylene(PP) film, oriented polypropylene (OPP) film, low density polyethylene(LDPE) film백에 담아 4 주 동안 $5^{\circ} \mathrm{C}$ 에 저장하면서, 이화학적 품질 특성을 측정하 였다.

\section{재료 및 방법}

\section{실험재료}

본 실험에서 사용한 배추는 전라남도 해남군에서 수확한 월동 배추를 사용하였으며, 세라믹 칼(DK A711-178, Dorco Co., Seoul, Korea)을 이용하여 배추를 일정한 크기 $(3 \times 3 \mathrm{~cm})$ 로 절단하여 PP film $(20 \times 30 \mathrm{~cm}, 45 \mu \mathrm{m}), \mathrm{OPP}$ film $(30 \times 20$ $\mathrm{cm}, 30 \mu \mathrm{m}), \mathrm{LDPE}$ film $(25 \times 30 \mathrm{~cm}, 30 \mu \mathrm{m})$ 백에 각각 150 $\mathrm{g}$ 씩 넣은 후 $5^{\circ} \mathrm{C}$ 에서 4 주 동안 저장하면서 실험에 사용하 였다.

\section{중량 감소율}

절단 배추의 중량 감소율은 처리 조건별로 시료를 취한 후 매주 칭량하여 초기 중량과 이후 측정된 시료의 중량을 초기 중량에 대한 백분율(\%)로 나타내었다.

\section{가용성 고형분 함량}

절단 배추의 가용성 고형분 함량은 배추 시료 $10 \mathrm{~g}$ 에 증류수 $10 \mathrm{~mL}$ 를 가하여 분쇄하고 여과한 여과액의 200 $\mu \mathrm{L}$ 를 취해 굴절 당도계로 측정하였다.

\section{적정산도 및 $\mathrm{pH}$}

절단 배추의 적정 산도는 배추 시료 $10 \mathrm{~g}$ 에 증류수 10 $\mathrm{mL}$ 를 가하여 분쇄하고 여과한 여과액 $1 \mathrm{~mL}$ 를 증류수 19 $\mathrm{mL}$ 와 혼합하여 20 배 희석한 시료를 $0.01 \mathrm{~N} \mathrm{NaOH}$ 로 $\mathrm{pH}$ 8.3 이 될 때까지 적정한 후 소비된 $\mathrm{NaOH}$ 의 양을 측정하여 구하였다(17). $\mathrm{pH}$ 는 20 배 희석한 시료를 $\mathrm{pH}$ meter로 측정하 였다.

\section{색차 및 갈변도}

절단 배추의 색차는 배추 3 조각을 표준 백색판 $(\mathrm{L}=97.79$, $\mathrm{a}=-0.38, \mathrm{~b}=2.05)$ 으로 보정된 colorimeter(CM-700d, Minolta Co., Osaka, Japan)를 사용하여 20회 반복하여 측정하여 $\mathrm{L}$ (lightness), $\quad \mathrm{a}$ (redness), $\quad \mathrm{b}$ (yellowness), $\quad \Delta \mathrm{E}=$ $\sqrt{\triangle L^{2}+\triangle a^{2}+\triangle b^{2}}$ 값으로 나타내었다(3).

\section{Film의 불투명도}

필름의 불투명도는 $\mathrm{Kim}$ 등의 방법에 따라 측정하였다
(18). 필름을 사각형 $(1 \times 4.5 \mathrm{~cm})$ 으로 자른 후 이를 분광분석 용 quartz cell의 빛 통과 영역에 부착시키고, 분광광도계 (UV1601, Shimadzu, Kyoto, Japan)를 이용하여 $600 \mathrm{~nm}$ 에서 흡광도를 측정하였다. 불투명도는 식 [Opacity $=\mathrm{A}_{600} / \mathrm{X}$ 에 의해 계산하였다. 이 때, $\mathrm{A}_{6000}$ 은 $600 \mathrm{~nm}$ 에서의 흡광도 값을 나타내며, $x$ 는 film의 두께를 나타낸다.

\section{관능검사}

관능검사는 경북대학교 식품공학과 학부 및 대학원생 25명을 대상으로 색, 냄새, 외관에 대하여 5점 기호 척도법 으로 실시하였다.

\section{통계분석}

모든 실험결과는 3 반복하여 평균(mean)五준편차 (standard deviation, SD)로 표시하였다. ANOVA 분석을 행 한 후 $\mathrm{p}<0.05$ 수준에서 Duncan's multiple range test를 실시 하여 유의성을 검증하였으며, SAS(9.3, SAS Institute Inc., Cary, NC, USA) 통계프로그램을 이용하였다.

\section{결과 및 고찰}

플라스틱 포장재는 유연성, 열 안정성, 차단성 등이 우수 하고 크기와 모양이 다양하여 식품의 포장재로 널리 이용되 고 있다. PP film은 기계적 강도, 열 차단성, 방습성, 기체 투과성, 투명도, 경제성이 우수하며, 비중이 0.9로 범용 플 라스틱 중에서 가장 가벼워 포장재로 수년간 사용되어 왔다 $(19,20)$. 이러한 PP film은 셀로판을 대체하며 우리 생활전 반에 걸쳐 사용되고 있으며, 크게 무연신 $\mathrm{PP}$ (cast polypropylene, CPP) film과 연신 PP(oriented polypropylene, OPP) film으로 나뉜다(20). OPP film은 polypropylene 재질 을 연신처리 한 것으로 차단성이 뛰어나 다양한 식품의 포장재로 사용되고 있다(21). LDPE film은 성형성이 뛰어 나고 열접착, 충격강도, 광학적 성질, 방수성, 유연성, 전기 적 성질, 내약품성이 우수하여 일반포장용, 농업용 등으로 널리 사용되고 있다(20). 본 연구에서는 식품 포장재로 널리 사용되는 PP, OPP, LDPE film을 이용하여 $5^{\circ} \mathrm{C}$ 에서 4주 동안 저장하면서 절단 배추의 이화학적 품질 특성을 조사 하였다.

\section{중량 감소율}

중량 감소는 저장 중 채소의 증산작용에 의한 것이며, 수분 손실과 관련이 있다(22-24). 따라서 과채류의 중량 보 존은 유통 및 판매과정에서 신선편이 제품의 시듦 현상을 방지하여 외관의 품질을 우수하게 유지하는데 필수적이다 $(25,26)$. 각 포장재에 따른 저장 중 배추의 중량 감소율을 측정한 결과는 Fig. 1 과 같다. 중량은 저장 4 주차에 이르기 
까지 유의적으로 감소하였으며, 포장재 종류에 따라 상이 한 감소율을 보였다. 저장 1 주차에는 모든 포장구에서 99.93 99.97\% 범위의 중량 감소율을 보였고, 저장기간이 지남에 따라 포장재에 따른 중량 감소율은 OPP film>LDPE film>PP film 순으로 높게 나타났다. OPP film으로 포장한 배추의 중량 감소율이 $0.24 \%$ 로 가장 높았으며, PP film과 LDPE film으로 포장한 배추는 4주 동안 99.80 99.82\%로 비슷한 감소율을 보였다. 따라서 PP film과 LDPE film으로 포장할 경우 수분 손실 억제로 인해 중량감소를 효과적으로 방지할 수 있다.

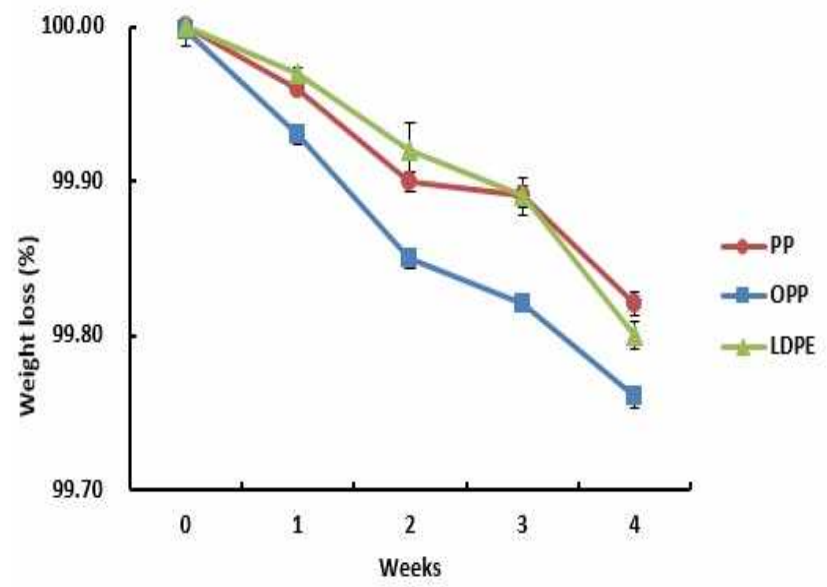

Fig. 1. Weight loss changes for cut kimchi cabbage with respect to packaging materials during short-term storage at $5^{\circ} \mathrm{C}$.

$\operatorname{PP}(\mathbf{O})$, polypropylene film; $\operatorname{OPP}(\square)$, oriented polypropylene film; $\operatorname{LDPE}(\boldsymbol{\Lambda})$, low density polyethylene film.

\section{가용성 고형분 함량}

가용성 고형분은 저장기간 중 호흡의 기질로 사용되어 감소한다고 보고되어 있다 $(3,27)$. 포장재에 따른 저장 중 배추의 가용성 고형분 함량 변화를 측정한 결과는 Table 1 과 같다. 저장기간의 차이는 다소 있으나 3 종류의 포장구

Table 1. Soluble solid content changes for cut kimchi cabbage with respect to packaging materials during short-term storage at $5^{\circ} \mathrm{C}$

\begin{tabular}{cccc}
\hline \multirow{3}{*}{ Weeks } & \multicolumn{3}{c}{ Package $^{\mathrm{l}}$} \\
\cline { 2 - 4 } & PP $\left({ }^{\circ}\right.$ Brix $)$ & OPP $\left({ }^{\circ}\right.$ Brix $)$ & LDPE $\left({ }^{\circ}\right.$ Brix $)$ \\
\hline 0 & $\left.1.80 \pm 0.20^{\mathrm{aB} 2}\right)$ & $1.80 \pm 0.20^{\mathrm{aA}}$ & $1.80 \pm 0.20^{\mathrm{aA}}$ \\
1 & $1.47 \pm 0.12^{\mathrm{bB}}$ & $1.67 \pm 0.15^{\mathrm{abA}}$ & $1.87 \pm 0.12^{\mathrm{aA}}$ \\
2 & $2.47 \pm 0.31^{\mathrm{aA}}$ & $1.77 \pm 0.35^{\mathrm{bA}}$ & $1.93 \pm 0.12^{\mathrm{abA}}$ \\
3 & $1.70 \pm 0.26^{\mathrm{aB}}$ & $1.83 \pm 0.12^{\mathrm{aA}}$ & $1.67 \pm 0.31^{\mathrm{aA}}$ \\
4 & $1.77 \pm 0.21^{\mathrm{aB}}$ & $1.60 \pm 0.20^{\mathrm{aA}}$ & $1.77 \pm 0.25^{\mathrm{aA}}$ \\
\hline
\end{tabular}

${ }^{1)} \mathrm{PP}$, polypropylene film; OPP, oriented polypropylene film; LDPE, low density polyethylene film.

2)ab Means followed by the same letters within the row of each cut kimchi cabbages are not significantly different $(\mathrm{p}<0.05) ;{ }^{\mathrm{AB}}$ means followed by the same letters within the column per parameter are not significantly different $(\mathrm{p}<0.05)$.
모두 증가하다가 다시 감소하는 경향을 보였다. 저장기간 중 다소 증가한 것은 중량감소 중 수분 감소에 따른 영향이 라고 사료된다. 그러나 저장 4주차의 결과를 보면 PP film과 $\mathrm{LDPE}$ film에 저장된 배추는 0 주차 대비 $0.03^{\circ} \mathrm{Brix}$ 감소하여 동일한 감소율을 보였고, OPP film에 저장된 배추는 0 주차 대비 $0.2^{\circ} \mathrm{Brix}$ 감소하여 품질에 영향을 미칠 것이라 생각된다.

\section{적정산도 및 $\mathrm{pH}$}

각 포장재에 따른 저장 중 배추의 적정산도 변화를 측정 한 결과는 Table 2 와 같다. 저장 1 주차에는 유의적인 차이를 보이지 않았으나, 저장 2,4 주차에서 포장구별로 유의적인 차이를 보였다. 모든 포장구의 적정산도는 저장 3 주차까지 증가하다가 이후 감소하는 경향을 보였다. 각 포장재에 따 른 산도 증가율은 LDPE film으로 포장한 배추가 초기 산도 $0.08 \pm 0.03 \%$ 에서 저장 4주차 째 $0.15 \pm 0.01 \%$ 로 증가율이 가 장 컸다. OPP film과 PP film으로 포장한 배추는 저장 3주차 째 각각 $0.16 \pm 0.02 \%, 0.16 \pm 0.00 \%$ 로 큰 증가율을 보였지만 LDPE film 포장구의 저장 3 주차 째 증가율과 유의차는 나타 나지 않았으며, 저장 4 주차 째 각각 $0.12 \pm 0.00 \%, 0.13 \pm$ $0.01 \%$ 로 증가율이 상대적으로 적었다. 배추의 적정산도의 증가는 젖산균에 의해 배추 내의 당분이 젖산 등의 유기산 으로 발효에 의해 일어난다(28). 따라서 저장기간 동안 OPP film과 PP film이 LDPE film에 비해 배추의 산화를 지연시 키는 것으로 나타났다.

Table 2. Titratable acidity changes for cut kimchi cabbage with respect to packaging materials during short-term storage at $5^{\circ} \mathrm{C}$

\begin{tabular}{cccc}
\hline \multirow{3}{*}{ Weeks } & \multicolumn{3}{c}{ Package $^{\mathrm{l}}$} \\
\cline { 2 - 4 } & $\mathrm{PP}(\%)$ & OPP $(\%)$ & LDPE $(\%)$ \\
\hline 0 & $0.08 \pm 0.03^{\mathrm{aC} 2}$ & $0.08 \pm 0.03^{\mathrm{aC}}$ & $0.08 \pm 0.03^{\mathrm{aB}}$ \\
1 & $0.08 \pm 0.01^{\mathrm{aC}}$ & $0.08 \pm 0.01^{\mathrm{aC}}$ & $0.08 \pm 0.01^{\mathrm{aB}}$ \\
2 & $0.10 \pm 0.00^{\mathrm{aBC}}$ & $0.08 \pm 0.01^{\mathrm{CC}}$ & $0.09 \pm 0.02^{\mathrm{abB}}$ \\
3 & $0.16 \pm 0.02^{\mathrm{aA}}$ & $0.16 \pm 0.00^{\mathrm{aA}}$ & $0.15 \pm 0.02^{\mathrm{aA}}$ \\
4 & $0.13 \pm 0.01^{\mathrm{bAB}}$ & $0.12 \pm 0.00^{\mathrm{BB}}$ & $0.15 \pm 0.01^{\mathrm{aA}}$ \\
\hline
\end{tabular}

${ }^{1)} \mathrm{PP}$, polypropylene film; OPP, oriented polypropylene film; LDPE, low density polyethylene film.

2ab Means followed by the same letters within the row of each cut kimchi cabbages are not significantly different $(\mathrm{p}<0.05) ;{ }^{\mathrm{AB}}$ means followed by the same letters within the column per parameter are not significantly different $(\mathrm{p}<0.05)$.

각 포장재에 따른 저장 중 배추의 $\mathrm{pH}$ 변화를 측정한 결과 는 Table 3 과 같다. 저장 직후 $\mathrm{pH}$ 는 $6.00 \pm 0.11$ 이었고, 저장 1 3주 동안은 큰 변화를 나타내지 않았으나 저장 4주차 째에는 증가하였다. 즉 저장 3 주차 째까지는 $\mathrm{pH}$ 에 영향을 주는 유기산 함량의 변화가 크지 않았기 때문이라고 생각되 며, 이는 Park 등(22) 밀감 실험에서의 결과와 유사한 결과 였다. 
Table 3. $\mathrm{pH}$ value changes for cut kimchi cabbage with respect to packaging materials during short-term storage at $5^{\circ} \mathrm{C}$

\begin{tabular}{cccc}
\hline \multirow{2}{*}{ Weeks } & \multicolumn{3}{c}{ Package $^{1)}$} \\
\cline { 2 - 4 } & PP & OPP & LDPE \\
\hline 0 & $6.00 \pm 0.11^{\mathrm{aB} 2)}$ & $6.00 \pm 0.11^{\mathrm{aB}}$ & $6.00 \pm 0.11^{\mathrm{aB}}$ \\
1 & $5.96 \pm 0.06^{\mathrm{aB}}$ & $5.82 \pm 0.04^{\mathrm{bC}}$ & $5.91 \pm 0.03^{\mathrm{aB}}$ \\
2 & $6.06 \pm 0.02^{\mathrm{aB}}$ & $5.82 \pm 0.09^{\mathrm{bC}}$ & $6.01 \pm 0.03^{\mathrm{aB}}$ \\
3 & $6.01 \pm 0.05^{\mathrm{aB}}$ & $5.96 \pm 0.11^{\mathrm{aBC}}$ & $5.95 \pm 0.14^{\mathrm{aB}}$ \\
4 & $6.36 \pm 0.06^{\mathrm{aA}}$ & $6.32 \pm 0.10^{\mathrm{aA}}$ & $6.41 \pm 0.05^{\mathrm{aA}}$ \\
\hline
\end{tabular}

${ }^{1)} \mathrm{PP}$, polypropylene film; OPP, oriented polypropylene film; LDPE, low density polyethylene film.

2)ab Means followed by the same letters within the row of each cut kimchi cabbages are not significantly different $(\mathrm{p}<0.05) ;{ }^{\mathrm{AB}}$ means followed by the same letters within the column per parameter are not significantly different $(p<0.05)$.

Table 4. Hunter color values changes for cut kimchi cabbage with respect to packaging materials during short-term storage at $5^{\circ} \mathrm{C}$

\begin{tabular}{|c|c|c|c|c|}
\hline & \multirow{2}{*}{ Weeks } & \multicolumn{3}{|c|}{ Package ${ }^{\text {1) }}$} \\
\hline & & PP & OPP & LDPE \\
\hline \multirow{5}{*}{$\mathrm{L}$} & 0 & $78.19 \pm 3.28^{\mathrm{b}(2)}$ & $80.17 \pm 2.83^{\mathrm{aA}}$ & $80.65 \pm 2.60^{\mathrm{aB}}$ \\
\hline & 1 & $80.34 \pm 0.68^{\mathrm{bB}}$ & $78.84 \pm 2.62^{\mathrm{cB}}$ & $81.81 \pm 1.88^{\mathrm{aB}}$ \\
\hline & 2 & $82.61 \pm 1.19^{\mathrm{bA}}$ & $79.67 \pm 1.11^{\mathrm{cAB}}$ & $83.76 \pm 1.81^{\mathrm{aA}}$ \\
\hline & 3 & $83.06 \pm 1.88^{\mathrm{aA}}$ & $78.64 \pm 0.85^{\mathrm{cB}}$ & $81.40 \pm 1.08^{\mathrm{bB}}$ \\
\hline & 4 & $76.15 \pm 3.53^{\mathrm{cD}}$ & $79.28 \pm 1.20^{\mathrm{bAB}}$ & $84.00 \pm 3.30^{\mathrm{aA}}$ \\
\hline \multirow{5}{*}{$\mathrm{a}$} & 0 & $-0.75 \pm 0.15^{\mathrm{aBC}}$ & $-0.83 \pm 0.20^{\mathrm{aA}}$ & $-0.80 \pm 0.18^{\mathrm{aB}}$ \\
\hline & 1 & $-0.6 \pm 0.08^{\mathrm{aA}}$ & $-0.85 \pm 0.37^{\mathrm{bA}}$ & $-1.01 \pm 0.34^{\mathrm{bC}}$ \\
\hline & 2 & $-0.69 \pm 0.08^{\mathrm{abB}}$ & $-0.71 \pm 0.06^{\mathrm{bA}}$ & $-0.66 \pm 0.04^{\mathrm{aA}}$ \\
\hline & 3 & $-0.83 \pm 0.11^{\mathrm{aC}}$ & $-1.14 \pm 0.33^{\mathrm{bB}}$ & $-1.05 \pm 0.25^{\mathrm{bC}}$ \\
\hline & 4 & $-0.82 \pm 0.12^{\mathrm{aC}}$ & $-0.88 \pm 0.21^{\mathrm{aA}}$ & $-0.87 \pm 0.13^{\mathrm{aB}}$ \\
\hline \multirow{5}{*}{$\mathrm{b}$} & 0 & $5.80 \pm 0.58^{\mathrm{a} A \mathrm{~B}}$ & $5.71 \pm 0.81^{\mathrm{aB}}$ & $5.62 \pm 0.71^{\mathrm{aBC}}$ \\
\hline & 1 & $5.73 \pm 0.65^{\mathrm{cAB}}$ & $6.61 \pm 0.58^{\mathrm{aA}}$ & $6.20 \pm 0.48^{\mathrm{bB}}$ \\
\hline & 2 & $5.71 \pm 0.44^{\mathrm{aAB}}$ & $4.81 \pm 0.39^{\mathrm{cC}}$ & $5.31 \pm 0.59^{\mathrm{bC}}$ \\
\hline & 3 & $5.97 \pm 0.41^{\mathrm{aA}}$ & $6.38 \pm 1.34^{\mathrm{aA}}$ & $6.24 \pm 1.02^{\mathrm{aB}}$ \\
\hline & 4 & $5.42 \pm 0.97^{\mathrm{bB}}$ & $5.55 \pm 0.65^{\mathrm{bB}}$ & $7.78 \pm 1.54^{\mathrm{aA}}$ \\
\hline \multirow{5}{*}{$\Delta \mathrm{E}$} & 0 & $22.21 \pm 3.14^{\mathrm{aB}}$ & $20.29 \pm 2.72^{b B}$ & $19.80 \pm 2.48^{\mathrm{bA}}$ \\
\hline & 1 & $20.11 \pm 0.65^{\mathrm{bC}}$ & $21.84 \pm 2.30^{\mathrm{aA}}$ & $18.88 \pm 1.87^{\mathrm{cAB}}$ \\
\hline & 2 & $17.95 \pm 1.17^{\mathrm{bD}}$ & $20.49 \pm 1.10^{\mathrm{aB}}$ & $16.72 \pm 1.87^{c \mathrm{C}}$ \\
\hline & 3 & $17.63 \pm 1.66^{\mathrm{cD}}$ & $21.95 \pm 1.19^{\mathrm{aA}}$ & $19.30 \pm 0.81^{\mathrm{bA}}$ \\
\hline & 4 & $24.07 \pm 3.60^{\mathrm{aA}}$ & $21.08 \pm 1.13^{\mathrm{bAB}}$ & $17.69 \pm 2.38^{\mathrm{CBC}}$ \\
\hline
\end{tabular}

${ }^{1)} \mathrm{PP}$, polypropylene film; OPP, oriented polypropylene film; LDPE, low density polyethylene film.

2)ab Means followed by the same letters within the row of each cut kimchi cabbages are not significantly different $(\mathrm{p}<0.05)$; ${ }^{\mathrm{A}}$ means followed by the same letters within the column per parameter are not significantly different $(\mathrm{p}<0.05)$.

\section{색차 및 갈변도}

신선편이 농산물에서 변색은 매우 중요한 품질변화 요인 으로 특히 표면 갈변은 매우 중요한 품질 지표로 작용하여
품질의 상품성을 좌우한다(29). 각 포장재에 따른 저장 중 절단 배추의 색도 변화는 색차계를 이용하여 측정하였고, 그 결과는 Table 4 와 같다. L값은 명도, $\mathrm{a}$ 는 적색도, $\mathrm{b}$ 는 황색도를 나타내고, $\triangle \mathrm{E}$ 값은 $\sqrt{\Delta L^{2}+\Delta a^{2}+\Delta b^{2}}$ 으로 나 타내었다. 명도 $\mathrm{L}$ 값은 저장 기간이 길어질수록 약간 감소하 는 경향을 보였으나, LDPE film 포장에서는 증가하는 경향 을 나타내었다. 적색도 $\mathrm{a}$ 값은 전체적으로 감소하는 경향을 나타내었고, 황색도 $\mathrm{b}$ 값은 LDPE film 포장을 제외하고 감 소하는 경향을 나타내었다. 저장 기간이 길어질수록 색차 는 전체적으로 감소하는 경향을 보였으나, 포장재에 따른 유의적인 차이는 나타나지 않았다.

\section{Film의 불투명도}

신선편이 농산물에서는 포장재에 담긴 상태의 외관상 신선도도 중요한 요소이다. 포장된 상태의 외관상 신선도 변화는 Fig. 2에 나타내었다. 포장재별로 투명도의 차이가 있었는데 이는 Fig. 3과 같다. PP film의 투명도가 OPP, LDPE film에 비하여 훨씬 높았다.

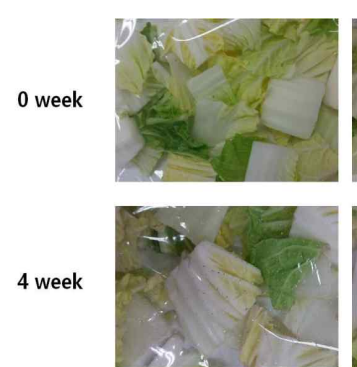

PP
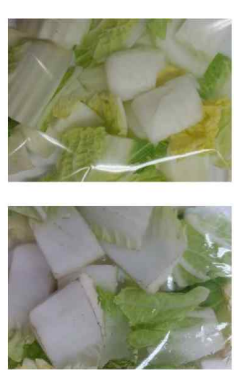

OPP
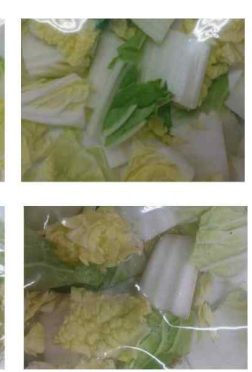

LDPE
Fig. 2. Appearance of cut kimchi cabbage for various packaging materials during short-term storage at $5^{\circ} \mathrm{C}$.

PP, polypropylene film; OPP, oriented polyproprylene film; LDPE, low density polyethylene film

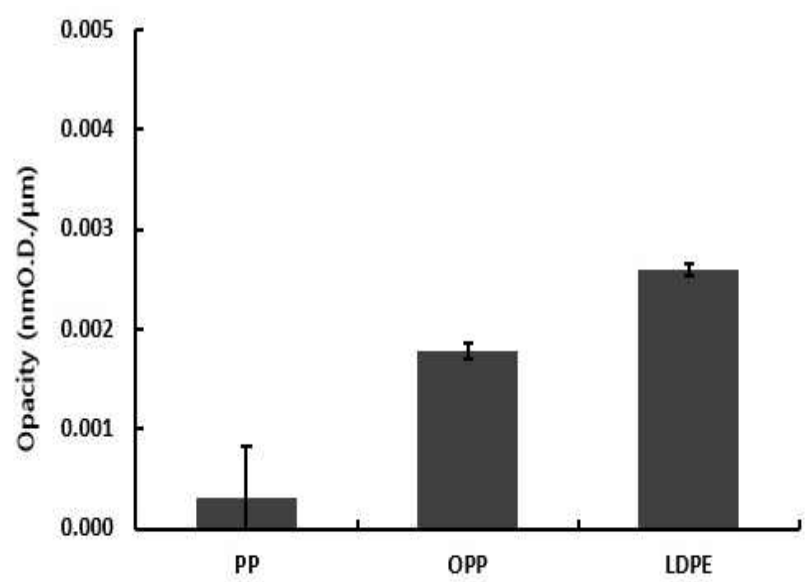

Fig. 3. Opacity values of the packaging materials used in this study. PP, polypropylene film; OPP, oriented polypropylene film; LDPE, low density polyethylene film. 
관능검사

절단배추의 저장 중 색, 풍미, 외관에 대하여 5 점 척도법 으로 측정한 결과는 Table 5 와 같다. 모든 포장구에서 저장 일수가 길어짐에 따라서 기호도 값들이 낮아졌다. 절단배 추의 색에 대한 평가에서는 저장 2 주차를 제외하고는 LDPE film 포장구가 가장 높은 값을 나타내었고, 저장 4주 차에서 $\mathrm{LDPE}>\mathrm{PP}>\mathrm{OPP}$ 순으로 높은 값을 나타내었지만 유 의적인 차이는 없었다. 풍미에서는 저장 1 주차에서 $\mathrm{OPP}$ 가 가장 높은 값을, 저장 2,3 주차에서는 $\mathrm{PP}$ 와 $\mathrm{OPP}$ 가 가장 높은 값을 나타내었고, 저장 4주차에서 $\mathrm{LDPE}, \mathrm{OPP}>\mathrm{PP}$ 순 으로 높은 값을 나타내었지만, 통계적으로 유의적인 차이 는 없었다. 전체적인 외관 특성에서는 각 주차별로 가장 높은 값을 가지는 포장재의 종류에 차이가 있었지만 저장 4주차에서 PP, LDPE가 OPP에 비해 높은 값을 나타내었고, $\mathrm{PP}$ 와 LDPE 사이의 유의적인 차이는 없었다.

Table 5. Sensory score changes for cut kimchi cabbage with respect to packaging materials during short-term storage at $5^{\circ} \mathrm{C}$

\begin{tabular}{|c|c|c|c|c|}
\hline \multirow{2}{*}{ Property } & \multirow{2}{*}{ Weeks } & \multicolumn{3}{|c|}{ Package } \\
\hline & & PP (point) & OPP (point) & LDPE (point) \\
\hline \multirow{5}{*}{ Color } & 0 & $5.0 \pm 0.0^{\mathrm{aA} 2)}$ & $5.0 \pm 0.0^{\mathrm{aA}}$ & $5.0 \pm 0.0^{\mathrm{aA}}$ \\
\hline & 1 & $4.8 \pm 0.4^{\mathrm{aA}}$ & $4.7 \pm 0.5^{\mathrm{aA}}$ & $5.0 \pm 0.0^{\mathrm{aA}}$ \\
\hline & 2 & $4.0 \pm 0.0^{\mathrm{aB}}$ & $4.7 \pm 0.5^{\mathrm{aA}}$ & $4.5 \pm 0.8^{\mathrm{aAB}}$ \\
\hline & 3 & $3.7 \pm 0.5^{\mathrm{aBC}}$ & $3.8 \pm 0.4^{\mathrm{aB}}$ & $4.2 \pm 0.8^{\mathrm{aB}}$ \\
\hline & 4 & $3.5 \pm 0.6^{\mathrm{aC}}$ & $3.0 \pm 0 . .^{9^{\mathrm{CC}}}$ & $3.8 \pm 0.4^{a^{\mathrm{B}}}$ \\
\hline \multirow{5}{*}{ Flavor } & 0 & $5.0 \pm 0.0^{\mathrm{aA}}$ & $5.0 \pm 0.0^{\mathrm{aA}}$ & $5.0 \pm 0.0^{\mathrm{aA}}$ \\
\hline & 1 & $4.8 \pm 0.4^{\mathrm{aAB}}$ & $5.0 \pm 0.0^{\mathrm{aA}}$ & $4.8 \pm 0 . .^{\mathrm{aA}}$ \\
\hline & 2 & $4.3 \pm 0.5^{a \mathrm{~B}}$ & $4.3 \pm 0.5^{\mathrm{aB}}$ & $4.2 \pm 0.4^{a^{\mathrm{B}}}$ \\
\hline & 3 & $3.7 \pm 0.5^{2 \mathrm{C}}$ & $3.7 \pm 0.5^{\mathrm{aC}}$ & $3.7 \pm 0.5^{2^{\mathrm{B}}}$ \\
\hline & 4 & $2.8 \pm 0.8^{\mathrm{aD}}$ & $3.0 \pm 0 . .^{\mathrm{aD}}$ & $3.0 \pm 0.9^{\mathrm{aC}}$ \\
\hline \multirow{5}{*}{ Appearance } & 0 & $5.0 \pm 0.0^{\mathrm{aA}}$ & $5.0 \pm 0.0^{\mathrm{aA}}$ & $5.0 \pm 0.0^{\mathrm{aA}}$ \\
\hline & 1 & $4.8 \pm 0.4^{\mathrm{aA}}$ & $4.7 \pm 0.5^{\mathrm{aAB}}$ & $4.8 \pm 0.0^{\mathrm{aA}}$ \\
\hline & 2 & $4.0 \pm 0.0^{6 \mathrm{~B}}$ & $4.3 \pm 0.5^{\mathrm{abBC}}$ & $4.7 \pm 0.5^{\mathrm{aA}}$ \\
\hline & 3 & $3.3 \pm 0.5^{2 \mathrm{C}}$ & $4.0 \pm 0.6^{\mathrm{aC}}$ & $3.8 \pm 0.5^{2^{\mathrm{B}}}$ \\
\hline & 4 & $2.8 \pm 0.8^{\mathrm{aC}}$ & $2.3 \pm 0.5^{\mathrm{aD}}$ & $3.0 \pm 0.9^{\mathrm{aC}}$ \\
\hline
\end{tabular}

${ }^{1)} \mathrm{PP}$, polypropylene film; OPP, oriented polypropylene film; LDPE, low density polyethylene film.

2)ab Means followed by the same letters within the row of each cut kimchi cabbages are not significantly different $(p<0.05) ;{ }^{A B}$ means followed by the same letters within the column per parameter are not significantly different $(\mathrm{p}<0.05)$.

\section{요 약}

절단 배추의 포장재에 따른 저장 중 품질변화를 알아보 기 위해 배추 $(3 \times 3 \mathrm{~cm})$ 를 PP film, OPP film, LDPE film백에 각각 넣은 후 $5^{\circ} \mathrm{C}$ 에서 4 주 동안 저장하면서 저장 특성을 조사하였다. 중량은 0.03 0.24\%의 범위로 감소하였으며,
PP film 포장구가 가장 낮은 감소율을 보였다. 가용성 고형 분 함량은 $0.03 \sim 0.2^{\circ} \mathrm{Brix}$ 의 범위로 감소하였으며, PP film 포장구가 낮은 감소율을 보였다. 적정산도는 모든 처리구 에서 증가하다가 감소하는 경향을 나타냈으나, PP film과 OPP film 포장구의 증가율이 낮았다. 색도값은 저장기간이 길어질수록 전체적으로 감소하였으나, 포장재에 따른 유의 적인 차이는 나타나지 않았다. 관능검사 결과 역시 포장재 에 따른 유의적인 차이가 나타나지 않았으나, 외관상 품질 특성은 PP film 포장구가 다른 포장보다 우수하였다. 따라 서 투명한 PP film으로 절단배추를 포장하여 저장 및 유통 하는 것이 선도 및 품질 유지에 효과적이라고 사료된다.

\section{감사의 글}

본 연구는 농림축산식품부·농림수산식품기술기획평 가원 첨단생산기술개발사업의 연구비 지원으로 수행되었 으며 이에 감사드립니다.

\section{References}

1. Seong GU, Chung HS, Chung SK (2015) The cutting process improvement for cut kimchi cabbages quality. Korean J Food Preserv, 22, 154-157

2. Kim SS, Ku KH, Jeong MC, Hong JH, Chung SK (2014) Effects of pre-heat pre-heat treatments on the quality of cut kimchi cabbages during short-term storage. Korean J Food Preserv, 21, 776-783

3. Kim SS, Seong GU, Hwang HY, Jeong MC, Chung SK (2014) The Short-term storage characteristics of cut kimchi cabbages treated with $\mathrm{Ca}^{2+}$. Korean J Food Preserv, 21, 157-162

4. Ahvenainen R (1996) New approaches in improving the shelf life of minimally processed fruit and vegetables. Korean J Food Sci Technol, 7, 179-186

5. Choi DJ, Lee YJ, Kim YK, Kim MH, Choi SR, Cha HS, Youn AR (2013) Effect of washing methods on the quality of freshly cut sliced Deodeok (Codonopsis lanceolata) during storage. Korean J Food Preserv, 20, 751-759

6. Eum HL, Bae SJ, Kim BS, Yoon JR, Kim JK, Hong SJ (2013) Postharvest quality changes of kimchi cabbage 'Choongwang' cultivar as influenced by postharvest treatments. Korean J Hort Sci Technol, 31, 429-436

7. Kim HB, Chung HS, Moon KD (2014) Browning inhibition of fresh-cut lotus roots by blanching in 
Glycyrrhiza glabra L. and Astragalus membranaceus Bunge extracts. Korean J Food Preserv, 21, 151-156

8. Song HJ, Kwon OY, Kang BH, Hur SS, Lee DS, Lee SH, Kang IK, Lee JM (2013) Change in quality attributes of fresh-cut potatoes with heat and browning inhibitor treatment during storage. Korean J Food Preserv, 20-386-393

9. Kang JS, Chung HS, Choi JU (2002) Effects of storage gas concentrations on the transpiration rate of Fuji apple during CA storage. Korean J Food Preserv, 9, 261-266

10. Lee HD, Yoon HS, Lee WO, Jeong H, Cho KH, Park WK (2003) Estimated gas concentrations of MA (modified atmosphere) and changes of quality characteristics during the MA storage on the oyster mushrooms. Korean J Food Preserv, 10, 16-22

11. Choi SY, Cho MA, Hong YP, Hwang IK, Chung DS, Yun SK (2011) Suppression of chilling injury and maintenance of quality characteristics in Prunus Mume fruits stored under controlled atmosphere. Korean J Food Preserv, 18, 143-148

12. Lee KS, Lee JC, Lee JK, Han KH, Oh MJ (2000) Shelf-life of red chili pepper on MA and CA storage. Korean J Postharvest Sci Technol, 7, 139-144

13. Kang JS, Hong GH (2001) Effects of storage gas concentrations on the qualities of garlic (Allium sativum L.) bulb during CA storage. Korean J Postharvest Sci Technol, 8, 258-263

14. Lee JW, Shin HS, Lee KH, Park JW (2009) Changes of physico-characteristics in green pumpkin during storage by packaging material and method. Korean J Food Sci Technol, 41, 374-379

15. Lee DU, Chang MS, Cho SD, Jhune CS, Kim GH (2013) Quality changes in mushrooms (Agaricus bisporus) due to their packaging materials during their storage. Korean J Food Preserv, 20, 7-13

16. Cha HS, Chung MS (2002) Changes in physicochemical characteristics of mature-green mume (Prunus mume Sieb. et Zucc) fruits as influenced by the thickness of packaging material. Korean J Food Preserv, 9, 148-153

17. AOAC (2000) Official Methods of Analysis 17th ed. Association of official analytical chemists. Washington DC, USA

18. Kim JY, Kim DH, Kim SB (2011) Physical properties of biofilm manufactured from gelatin of yellowfin tuna Thunnus albacares skin treated with acetic acid. Korean J Fish Aquat Sci, 44, 591-596

19. van Willige RWG, Linssen JPH, Meinders MBJ, van der Stege HJ, Voragen AGJ (2002) Influence of flavour absorption on oxygen permeation through LDPE, PP, PC and PET plastics food packaging. Food Addit Contam, 19, 303-313

20. Kang GB (2003) Introduction to market and manufacturing of polyolefin film. Polymer Sci Technol, 14, 154-162

21. Hwang TY (2013) Quality characteristics of soybean sprouts packaged with different packaging materials during their storage. Korean J Food Preserv, 20, 602-607

22. Park WP, Kim CH, Cho SH (2006) Quality characteristics of cherry tomato and unshiu orange packed with box incorporated with antimicrobial agents. Korean J Food Preserv, 13, 273-278

23. Lee HJ, Jang JH, Kwon JH, Moon KD (2009) Effect of packaging materials on the quality of radish sprout during storage. Korean J Food Preserv, 16, 147-154

24. Park JE, Kim HM, Hwang SJ (2012) Effect of harvest time, precooling, and storage temperature for keeping the freshness of 'Maehyang' strawberry for export. J Bio-Environment Control, 21, 404-410

25. Chang MS, Park MJ, Kim JG, Kim GH (2012) Effects of various packaging materials on the quality of heat treated lotus roots during storage. Korean J Food Preserv, $19,807-812$

26. Hong SI, Son SM, Chung MS, Kim DM (2003) Storage quality of minimally processed onions as affected by seal-packaging methods. Korean J Food Sci Technol, 35, 1110-1116

27. Jorg A, Monica F, Renato A (1992) Changes in sugars, acids, and amino acids during ripening and storage of apples (cv. Glockenapfel). J Agric Food Chem, 40, 1131-1134

28. Han ES, Seok MS, Park JH (1998) Quality changes of salted Baechu with packaging methods during long term storage. Korean J Food Sci Technol, 30, 1307-1311

29. Sun SH, Kim SJ, Kim GC, Kim HR, Yoon KS (2011) Changes in quality characteristics of fresh-cut produce during refrigerated storage. Korean J Food Sci Technol, 43, 495-503 